\title{
Childhood cancer and drugs in pregnancy
}

\author{
B M SANDERS, G J DRAPER
}

British Medical fournal, 1979, 1, 718-719

\section{Summary and conclusions}

A study was carried out on 11169 matched case-control pairs of children aged up to 15 years included in the Oxford Survey of Childhood Cancers to see whether an association exists between cancer in children and drugs given to their mothers during pregnancy. The mothers of children who developed cancer reported about $25 \%$ more illnesses during pregnancy than mothers of healthy control children. Two specific illnesses, pulmonary tuberculosis and epilepsy, were investigated. For these there was a higher than average case-control excess of reports and there had been a suggestion that the drugs used in treatment, isoniazid and phenytoin, might be carcinogenic.

The results of this investigation provide no real evidence for any association between the drugs taken by the mothers during pregnancy and subsequent cancer in the child.

\section{Introduction}

The observation ${ }^{1}$ that cases of clear-cell vaginal adenocarcinoma in young women followed administration of diethylstilbestrol to their mothers during pregnancy has stimulated discussion on whether other drugs could cross the placenta and cause cancer in the offspring. Gold et $a l,{ }^{2}$ in a case-control study of the antenatal histories of women whose children developed brain tumours, suggested that a small proportion of brain tumours in children may be attributable to barbiturates taken either by the mother prenatally or by the child.

We have studied the reports of certain illnesses suffered during pregnancy by mothers whose children developed cancer and by mothers of healthy control children and have compared the frequency with which certain drugs were prescribed for the two groups of mothers. Two drugs-namely, isoniazid and phenytoin-are of particular interest. Several cases of lymphomas associated with the use of phenytoin have occurred,

Childhood Cancer Research Group, University of Oxford Department of the Regius Professor of Medicine, Oxford OX1 9QG

B M SANDERS, BA, research officer

G J DRAPER, MA, DPHIL, director and at least three reports describe tumours developing in children with phenytoin-related congenital defects. ${ }^{3-5}$ Experiments have shown that isoniazid is carcinogenic in mice, and concern has been expressed that it might also be carcinogenic in humans.

\section{Method and results}

A total of 11169 matched case-control pairs of children (5210 aged $0-4$ years, 3684 aged 5-9, and 2275 aged 10-15) were included in the Oxford Survey of Childhood Cancers between 1953 and 1971. The mothers of children who developed cancer reported about $25 \%$ more illnesses during pregnancy than the mothers of control children. Some of the illnesses that were reported as being more common among the former group of mothers were ill-defined conditions such as migraine, sciatica, and accidental injuries. Understandably, a mother whose child has developed cancer is more likely to remember and report such events than a mother whose child has remained healthy. When these categories were excluded, however, several serious illnesses remained for which there was a greater than average excess of reports among the mothers of children with cancer. Some of these findings might be attributable to chance, and in the absence of any convincing alternative we may reasonably accept this explanation.

For two illnesses-namely, pulmonary tuberculosis and epilepsywhere the case:control ratio was particularly high, there was also the possibility that two of the drugs used in treatment (isoniazid and phenytoin) might be carcinogenic to the fetus. If the apparent association between childhood cancer and a maternal illness were found to be specific to a particular drug this would provide some evidence that the association was not simply due to chance or reporting bias. In order to see whether this was the case, and to check on the mothers' statements, reports of these two illnesses were followed up by writing to general practitioners or hospitals for confirmation of the diagnosis and for details of the drugs used in treatment. Some of the antenatal records (some dating back to 1943) had been destroyed, but examination of those medical records that were available showed little difference in the proportions of mothers in the two groups who were prescribed particular drugs. The table gives the results of the study. For some women more than one drug was prescribed, and others received no drug treatment during pregnancy.

\section{Discussion}

An association appears to exist between certain illnesses occurring during pregnancy and subsequent cancer in the child. If this were attributable to particular drugs used in treating these maternal illnesses a stronger association between such drugs and the cancer might be expected. The results given here do not support this. The mothers' illnesses might also be expected to be associated with specific tumours rather than

Numbers of mothers reporting epilepsy and pulmonary tuberculosis during pregnancy (and proportions of those whose medical records could be traced who were treated with specified drugs)

\begin{tabular}{|c|c|c|c|c|c|c|c|c|c|}
\hline & & & & \multirow[t]{2}{*}{ No of reports } & \multirow{2}{*}{ No of medical records } & \multicolumn{4}{|c|}{ No $(\%)$ receiving treatment } \\
\hline & & & & & & Phenytoin & Phenobarbitone & Isoniazid & Streptomycin \\
\hline \multicolumn{10}{|c|}{ Epilepsy } \\
\hline $\begin{array}{l}\text { Cases } \\
\text { Controls }\end{array}$ & .. & $\ldots$ & .. & $\begin{array}{l}39 \\
22\end{array}$ & $\begin{array}{l}30 \\
18\end{array}$ & $\begin{array}{r}11(37) \\
7(39)\end{array}$ & $\begin{array}{l}20(67) \\
12(67)\end{array}$ & & \\
\hline \multicolumn{10}{|c|}{ Pulmonary tuberculosis } \\
\hline $\begin{array}{l}\text { Cases } \\
\text { Controls }\end{array}$ & $\because$. & $\because$ & .. & $\begin{array}{l}27 \\
13\end{array}$ & $\begin{array}{r}17 \\
9\end{array}$ & & & $\begin{array}{l}7(41) \\
5(56)\end{array}$ & $\begin{array}{l}6(35) \\
3(33)\end{array}$ \\
\hline
\end{tabular}


with childhood malignant disease in general. We found that in children of mothers with epilepsy six of the 39 tumours were lymphomas (ICD, ninth revision, categories 200-202); of these six children, one was classified as having Letterer-Siwe disease and two were brothers whose tumours were classified as familial histiocytosis. If the proportion of lymphomas had been the same as that in the study as a whole, four cases would have been expected; similarly, in the children of mothers reporting tuberculosis five of the 27 tumours were lymphomas, whereas two would have been expected.

$\mathrm{Li}$ et $a l^{6}$ suggested that there is an association between phenytoin and lymphomas; in this study, however, five of the mothers whose children developed lymphomas had been treated with phenobarbitone during pregnancy and none had received phenytoin.

While the slight excess of lymphomas found in the present study is of some anecdotal interest, the results reported here do not really provide any evidence of a transplacental drug effect in the aetiology of childhood cancer. Other illnesses during pregnancy may possibly have been treated by drugs that are carcinogenic to the fetus. Some degree of reassurance, however, may be derived from the present study, since we considered two of the illnesses most likely to yield positive results yet found no association between drugs used to treat them and cancer in children.

We thank Dr Alice Stewart, who collected the original data in the Oxford Survey of Childhood Cancers, and Dr L M Kinnier Wilson for her help in abstracting the data for this report.

The Childhood Cancer Research Group is supported by grants from the Department of Health and Social Security and the Scottish Home and Health Department.

\section{References}

${ }^{1}$ Herbst, A L, Ulfelder, H, and Poskanzer, D C, New England fournal of Medicine, 1971, 284, 878.

2 Gold, E, et al, fournal of the National Cancer Institute, 1978, 61, 1031.

3 Pendergrass, T W, and Hanson, J W, Lancet, 1976, 2, 150.

${ }^{4}$ Sherman, S, and Roizen, N, Lancet, 1976, 2, 517.

5 Blattner, W A, et al, fournal of the American Medical Association, 1977, 238, 334.

${ }^{6} \mathrm{Li}, \mathrm{F} \mathrm{P}$, et al, Cancer, 1975, 36, 1359.

(Accepted 23 fanuary 1979)

\section{SHORT REPORTS}

\section{Survival after major burn complicated by gas gangrene, acute renal failure, and toxic myocarditis}

Patients with burns who develop acute renal failure or gas gangrene rarely survive. We describe a patient who survived both these complications and believe that with early and aggressive treatment the outlook in such cases may be improved.

\section{Case report}

A 36-year-old man sustained a $53 \%$ burn (30\% full-thickness) of trunk, thighs, and left arm from burning petrol. After resuscitation he was transferred to the McIndoe Burns Unit. Relieving incisions through the deep circumferential burn of the arm were performed immediately, and on the fourth day this burn was excised and grafted (see figure). Over the next

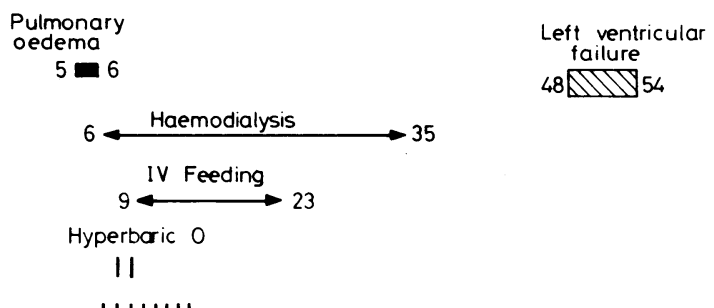

IIIIIIIII

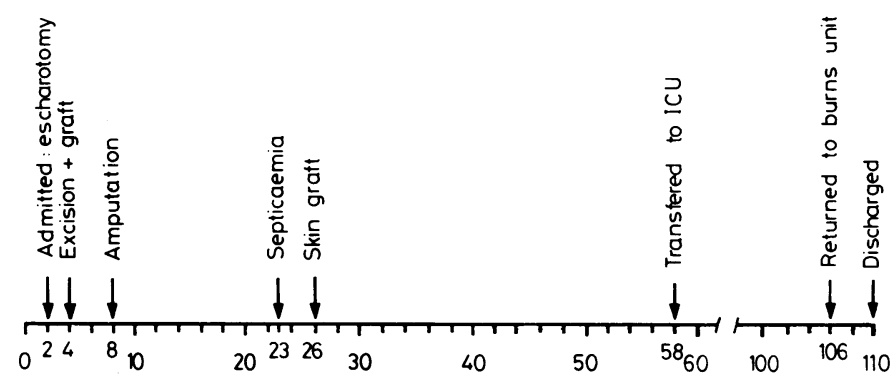

Time after burn (in days) of each major event. two days urinary osmolality became fixed at $320 \mathrm{mmol}(\mathrm{mosmol}) / \mathrm{kg}$, although urine output remained at about $21 / 24 \mathrm{~h}$. Plasma urea rose to $23 \mathrm{mmol} / \mathrm{l}$ $(139 \mathrm{mg} / 100 \mathrm{ml})$ and pulmonary oedema developed. Non-oliguric acute renal failure was diagnosed, and on the sixth day haemodialysis was started by the mobile dialysis unit.

On the seventh day gas gangrene of the left arm was diagnosed clinically and confirmed by culture of Clostridium welchii. The patient's condition precluded immediate operation, and treatment with hyperbaric oxygen was instituted by the mobile hyperbaric unit. Intravenous benzylpenicillin and metronidazole were started. One hour's treatment in the hyperbaric chamber, at three atmospheres absolute pressure, was given on 10 occasions over seven days until three consecutive bacteriological cultures were negative. On the eighth day the left arm was amputated by disarticulation at the shoulder. Daily haemodialysis was continued for $\mathbf{3 0}$ days. Total parenteral nutrition was given for the first two weeks until oral and nasogastric intakes were adequate. Plasma urea was kept below $30 \mathrm{mmol} / 1(181 \mathrm{mg} / 100 \mathrm{ml})$ and catabolism was controlled, there being an average rise in urea of $10 \mathrm{mmol} / \mathrm{l}$ $(60 \mathrm{mg} / 100 \mathrm{ml})$ between dialyses.

On the 23rd day the patient developed Escherichia coli septicaemia, which was treated successfully with intravenous amikacin. On the 28th day skin grafts were taken from the legs and the back was grafted. Two weeks after dialysis had been discontinued he developed left ventricular failure with rapid atrial flutter, thought to be caused by a toxic myocarditis. Digoxin and frusemide were given and he was transferred to an intensive care unit (ICU). His anaemia (haemoglobin $6 \mathrm{~g} / \mathrm{dl}$ ) was thought to be aggravating the cardiac failure, and fresh packed red cells were given. Transfusion had been withheld till then because of its adverse effect on recovering renal function.

He was discharged home on the 110th day with a creatinine clearance of $66 \mathrm{ml} / \mathrm{min}$. Three months fater he had made an excellent physical and psychological recovery.

\section{Comment}

We can find only 11 reported cases of burned patients surviving acute renal failure and have recently described a further four. ${ }^{1}$ Seven of these 15 patients had limb amputations. We can find only five reported cases of burned patients surviving gas gangrene. ${ }^{2}$

Several factors probably contributed to the successful outcome in the present case. Early recognition of non-oliguric renal failure permitted prompt and adequate dialysis. This improved the prognosis by keeping the blood urea below $33 \mathrm{mmol} / \mathrm{l}(199 \mathrm{mg} / 100 \mathrm{ml})^{3}$ and removing enough fluid to allow adequate feeding. ${ }^{4}$ Hyperbaric oxygen treatment of a patient moribund with gas gangrene improved his condition enough to permit operation, which removed a source of infection and possibly burn "toxin." Despite the large burn, a major operation, septicaemia, myocarditis, and anaemia the patient healed satisfactorily and did not develop progressive pulmonary insufficiency. This was almost certainly due to the control of catabolism by adequate 